\title{
Temporal changes in the secondary prevention of coronary artery disease in patients following myocardial revascularization
}

\author{
Paweł Kozieł ${ }^{1}$, Piotr Jankowski ${ }^{1}$, Sławomir Surowiec ${ }^{1}$, Piotr Bogacki ${ }^{2}$, Piotr Gomuła ${ }^{3}$, Ewa Mirek-Bryniarska ${ }^{4}$, \\ Jadwiga Nessler ${ }^{5}$, Piotr Podolec ${ }^{6}$, Marek Rajzer $^{1}$, Danuta Czarnecka ${ }^{1}$ \\ ${ }^{1}$ First Department of Cardiology, Interventional Electrocardiology and Hypertension, Institute of Cardiology, Jagiellonian University \\ Medical College, Krakow, Poland \\ ${ }^{2}$ Department of Cardiology, Ludwik Rydygier District Hospital, Krakow, Poland \\ ${ }^{3}$ Department of Cardiology, Gabriel Narutowicz Memorial General Hospital, Krakow, Poland \\ ${ }^{4}$ Department of Cardiology, Jozef Dietl Hospital, Krakow, Poland \\ ${ }^{5}$ Department of Coronary Heart Disease, Institute of Cardiology, Jagiellonian University, Medical College, Krakow, Poland \\ ${ }^{6}$ Department of Cardiac and Vascular Diseases, Institute of Cardiology, Jagiellonian University Medical College, Krakow, Poland
}

Adv Interv Cardiol 2020; 16, 4 (62): 422-428

DOI: https://doi.org/10.5114/aic.2020.101767

\begin{abstract}
A bstract
Introduction: Well-organized, effective secondary prevention of coronary artery disease (CAD) has a potential to improve the patients' prognosis following myocardial revascularization procedures.

Aim: To evaluate overtime changes in the implementation of the ESC guidelines for secondary prevention by assessing control of the main risk factors and the rate of cardioprotective drug use in patients following myocardial revascularization procedures.

Material and methods: Patients aged < 81 years who had been hospitalized for a myocardial revascularization procedure in five hospitals serving Krakow and surrounding districts were recruited and interviewed 6-18 months following discharge. Their personal medical history, medication use and control of the main cardiovascular risk factors were evaluated using a standard questionnaire in 2006-2007, 2011-2013, and 2016-2017. The same five hospitals took part in surveys on each occasion.

Results: We examined 260 patients in 2006-2007, 200 in 2011-2013 and 190 in 2016-2017. We noted a significant difference in the management of surveys participants: $62 \%$ underwent percutaneous coronary intervention ( $\mathrm{PCl}$ ) and $38 \%$ coronary artery coronary artery bypass grafting (CABG) in 2006-2007 whereas the corresponding proportions in 2016-2017 were 90\% and 10\%. The proportion of patients who did not achieve target blood pressure (according to ESC guidelines valid at the time of each survey) in 2006-2007, 2011-2013 and 2016-2017 was 53.5\%, 52.3\%, and 38.9\%, respectively, the proportion of those who did not achieve the LDL cholesterol target (according to ESC guidelines valid at the time of each survey) was $36.3 \%, 64.0 \%$, and $61.7 \%$, respectively, and the proportion of those with high fasting glucose was $12.6 \%, 14.6 \%$, and $19.7 \%$, respectively. The proportion of smokers was $16.2 \%, 19.5 \%$, and $16.8 \%$, whereas $30.5 \%, 28.6 \%$ and $40.5 \%$ of patients were obese in 2006-2007, 2011-2013 and 2016-2017, respectively. The proportion of patients taking antiplatelets ( $91.8 \%$ vs. $92.0 \%$ vs. $96.3 \%), \beta$-blockers ( $90.3 \%$ vs. $87.5 \%$ vs. $92.6 \%$ ), and lipid-lowering drugs ( $88.7 \%$ vs. $91.0 \%$ vs. $93.7 \%$ ) did not change significantly.

Conclusions: The analysis of three multicenter surveys provides evidence of the considerable potential for a further reduction in cardiovascular risk in patients following elective myocardial revascularization in Poland.
\end{abstract}

Key words: coronary artery disease, risk factors, secondary prevention, coronary artery bypass grafting, percutaneous coronary intervention.

Sum mary

The aim of this study was to evaluate the implementation of the guidelines for secondary prevention of coronary artery disease in patients following non-emergency coronary artery bypass grafting or percutaneous coronary intervention. Control of risk factors and cardioprotective drug use was similar in patients who had undergone percutaneous or surgical revascularization. The analysis of three multicenter surveys provides evidence of a persistent potential for further improvement in cardiovascular risk in revascularized patients.

\section{Corresponding author:}

Prof. Piotr Jankowski, First Department of Cardiology, Interventional Electrocardiology and Hypertension, Institute of Cardiology, Jagiellonian University Medical College, Krakow, Poland, e-mail: piotrjankowski@interia.pl

Received: 24.06.2020, accepted: 12.10 .2020$. 


\section{Introduction}

Cardiovascular diseases are a leading cause of mortality in developed countries [1]. Despite advances in the pharmacological and invasive treatment of coronary artery disease (CAD) in recent years the risk of recurrent cardiovascular events in patients with CAD remains high $[2,3]$. Patients who have undergone an elective myocardial revascularization procedure also constitute a very high cardiovascular risk group and have the most to gain from secondary prevention [4]. One of the most important factors increasing the risk of mortality in patients with established CAD is still unsatisfactory secondary prevention including lifestyle changes, control of risk factors and pharmacotherapy [4-8].

\section{Aim}

The aim of the present analysis was to evaluate temporal changes in the implementation of European Society of Cardiology (ESC) guidelines for secondary prevention by assessing control of the main risk factors and the rate of cardioprotective drug use in patients following myocardial revascularization procedures.

\section{Material and methods}

We analyzed the data of participants from three surveys appraising secondary prevention in patients with established CAD in 2006-2007, 2011-2013, and 20162017 [9-11]. The same five hospitals providing cardiological care in the city and surrounding districts participated in each survey. The methods used in surveys had been published previously and were similar each time [9-11]. Briefly, patients aged $<81$ years and hospitalized for an acute coronary syndrome or a myocardial revascularization procedure were recruited and interviewed 6-18 months after discharge from hospital. The inclusion criteria for the present analysis were elective percutaneous coronary intervention $(\mathrm{PCl})$ or scheduling for coronary artery bypass grafting (CABG). A patient's personal medical history, lifestyle and medications used were evaluated using a standard questionnaire. Diabetes status was determined based on the diagnosis found in the discharge letter. Smoking status was verified by assessing the concentration of breath carbon monoxide using a Smokerlyzer (Bedfont Scientific). Height and weight were measured in a standing position without shoes and heavy outwear using standard scales with a vertical ruler (SECA). Body mass index (BMI) was calculated according to the following formula: $\mathrm{BMI}=$ weight $[\mathrm{kg}] /(\text { height }[\mathrm{m}])^{2}$. Waist circumference was measured using a metal tape measure placed horizontally in the mid-axillary line, midway between the lowest rim of the rib cage and the tip of the hip bone with the patient in a standing position. Blood pressure was measured twice, on the right arm in a sitting position after at least 5 min of rest using an automatic device. The mean of two readings was used for the present analysis. A fasting venous blood sample was taken to measure plasma lipid and glucose levels. Glycated hemoglobin $\left(\mathrm{HbA}_{1 c}\right)$ was not measured in 2006-2007 and was only recorded in half of the participants in the survey in 2011-2013. The blood samples were analyzed in the central laboratory. The same laboratory was used in each survey. For the present report, we used the results of analyses performed no later than $12 \mathrm{~h}$ after blood collection.

We analyzed the proportions of patients with risk factors not at recommended goals: smoking, a fasting glucose level $\geq 7.0 \mathrm{mmol} / \mathrm{l}, \mathrm{BMI} \geq 25 \mathrm{~kg} / \mathrm{m}^{2}$, waist circumference $\geq 88 \mathrm{~cm}$ in women and $\geq 102 \mathrm{~cm}$ in men. In the case of blood pressure and low-density lipoprotein (LDL) cholesterol two approaches were adopted. First, we analyzed the proportions of patients achieving goals recommended at the time of each survey. Second, we also analyzed the proportions of patients with blood pressure and LDL cholesterol levels above the goal values recommended at the time of the final survey.

The secondary prevention coefficient was calculated in the following way: one point was given for each controlled risk factor (non-smoking, blood pressure at goal, LDL cholesterol at goal, glucose $<7.0 \mathrm{mmol} / \mathrm{l}$, BMI $<25$ $\mathrm{kg} / \mathrm{m}^{2}$ ) during the follow-up examination. The goal values for blood pressure and LDL cholesterol were based on the ESC guidelines, which were valid at the time each survey was conducted. Additionally, one point was given for taking an antiplatelet agent and an ACE inhibitor or an angiotensin II receptor antagonist. Thus, a patient's secondary prevention coefficient could vary from 0 to 7 .

The surveys protocols were approved by the institutional Bioethics Committee. All the patients signed an informed consent form.

\section{Statistical analysis}

Categorical variables were reported as percentages and continuous variables as means \pm standard deviation. The Pearson $\chi^{2}$ test was applied to all the categorical variables. Normally distributed continuous variables were compared using Student's $t$ test or analysis of variance. Variables without normal distributions were evaluated using the Mann-Whitney $U$ test or the Kruskal-Wallis analysis of variance. Generalized linear models as implemented in the Statistica 13 software (TIBCO Software, USA) were used to compare proportions after adjustment for age, sex, procedure, duration of education, professional activity, and period of time from discharge to the examination. Factors independently related to the secondary prevention coefficient were evaluated using multivariable regression analysis. A two-tailed $p$-value of less than 0.05 was regarded as statistically significant.

\section{Results}

We examined 260 patients in 2006-2007 (participation rate 84.1\%), 200 in 2011-2013 (60.2\%) and 190 pa- 
tients in 2016-2017 (72.8\%). The characteristics of the studied groups are presented in Table I. Participants of the third (2016-2017) survey were older, better educated and more likely to be employed compared to the participants of the first (2006-2007) and second (2011-2013) surveys. There was no significant difference in gender distribution between the surveys. A statistically significant decrease in the proportion of post-CABG patients was observed in each successive study.

Mean diastolic blood pressure and LDL cholesterol levels decreased over time, while no significant differences were observed in systolic blood pressure, glucose levels, $\mathrm{HbA}_{1 c}$ levels, or $\mathrm{CO}$ in exhaled air between the surveys (Table II). Differences in the proportion of patients who did not reach treatment goals 6-18 months after discharge from hospital adjusted for a number of co-factors are shown in Table III. The was no significant difference in proportion of patients with fasting glucose $\geq 7.0$ $\mathrm{mmol} / \mathrm{l}$ among those with diagnosed diabetes: $44.3 \%$ in $2006-2007$ vs. $44.9 \%$ in 2016-2017 ( $p=N S$ ).

After multivariable adjustments we did not observe any statistically significant difference in the use of antiplatelets (91.8\% in 2006-2007 vs. 96.3\% in 2016-2017), $\beta$-blockers $(90.3 \%$ in $2006-2007$ vs. $92.6 \%$ in $2016-$ 2017), or lipid-lowering drugs (88.7\% in 2006-2007 vs. 93.7\% in 2016-2017) 6-18 months after discharge from hospital (Table IV). In the same time, the proportion of patients reporting the use of calcium antagonists, diuretics, antidiabetics agents and anticoagulants increased significantly.

The mean secondary prevention coefficient was 4.79 \pm 1.07 (median value: 5 ; first quartile: 4 ; third quartile 6 ) in 2006-2007, $4.42 \pm 1.14$ (median value: 4; first quartile: 4; third quartile 5) in 2011-2013 ( $p<0.001$ vs. 2006-
2007), and $4.67 \pm 1.04$ (median value: 5 ; first quartile: 4; third quartile 5) in 2016-2017 ( $p=0.26$ vs. 2006-2007). Its value was equal to 7 in just $2.4 \%$ of patients in 2006 $2007,1.7 \%$ in $2011-2013$, and $1.6 \%$ in $2016-2017$, while $25.4 \%$ of survey participants in 2006-2007, $18.0 \%$ in 2011-2013, and $22.3 \%$ in 2016-2017 had a secondary prevention coefficient of at least $6(p=0.20)$. Figure 1 presents the mean secondary prevention coefficient values according to myocardial revascularization procedure and survey. Age, education and participation in second survey as compared to the first survey were related to the value of the secondary prevention coefficient in multivariable analysis (Table V).

\section{Discussion}

Results of the EUROASPIRE surveys demonstrated the potential for further improvement in cardiovascular risk in patients with CAD $[6,8]$. Lifestyle changes, control of risk factors and appropriate pharmacotherapy are major factors reducing the risk of cardiovascular events in CAD patients. The goal of elective myocardial revascularization is to alleviate symptoms in patients with angina and improve prognosis [12-14]. Although recently published results of the ISCHEMIA trial showed no significant influence of myocardial revascularization on cardiovascular event risk in patients with stable CAD, it showed a significant influence on angina, quality of life and physical performance $[15,16]$. Several previous studies have also shown that myocardial revascularization is not only more effective in reducing angina and the need for antianginal drugs, but also improves physical performance and quality of life compared to the conservative treatment strategy both in a short- and long-term follow-up [17, 18]. However, the failure to properly implement lifestyle changes may

Table I. Characteristics of the study group by survey

\begin{tabular}{|c|c|c|c|c|}
\hline Parameter & $\begin{array}{c}2006-2007 \\
N=260\end{array}$ & $\begin{array}{c}2011-2013 \\
N=200\end{array}$ & $\begin{array}{c}2016-2017 \\
N=190\end{array}$ & $\begin{array}{c}\text { Total } \\
N=650\end{array}$ \\
\hline Age [years] & $62.6 \pm 8.9$ & $64.2 \pm 7.9$ & $67.0 \pm 7.3^{* \dagger}$ & $64.4 \pm 8.4$ \\
\hline \multicolumn{5}{|l|}{$\operatorname{Sex}(\%):$} \\
\hline Men & 77.3 & 77.5 & 80.5 & 78.3 \\
\hline Women & 22.7 & 22.5 & 19.5 & 21.7 \\
\hline Duration of education [years] & $11.8 \pm 3.3$ & $11.6 \pm 3.0$ & $13.0 \pm 3.3^{\star \dagger}$ & $12.1 \pm 3.3$ \\
\hline Employed (\%) & 37.4 & $24.0^{*}$ & 30.0 & 31.1 \\
\hline Diabetes (\%) & 23.5 & $36.0^{*}$ & $36.3^{*}$ & 31.1 \\
\hline \multicolumn{5}{|l|}{ Index event (\%): } \\
\hline$\overline{\mathrm{PCl}}$ & 62.3 & 70.5 & $90.0^{\star \dagger}$ & 72.9 \\
\hline$\overline{C A B G}$ & 37.7 & 29.5 & $10.0^{* \dagger}$ & 27.1 \\
\hline $\begin{array}{l}\text { Time from discharge from the hospital } \\
\text { to the follow-up examination [years] }\end{array}$ & $1.18 \pm 0.40$ & $1.05 \pm 0.21^{*}$ & $0.82 \pm 0.29^{* \dagger}$ & $1.03 \pm 0.38$ \\
\hline
\end{tabular}

CABG - coronary artery bypass grafting, PCl - percutaneous coronary intervention. ${ }^{*} p<0.05$ vs. 2006-2007, ${ }^{+} p<0.05$ vs. $2011-2013$. 
Table II. Temporal changes in the risk factors 6-18 months after discharge

\begin{tabular}{|c|c|c|c|c|}
\hline Parameter & $\begin{array}{c}2006-2007 \\
N=260\end{array}$ & $\begin{array}{c}2011-2013 \\
N=200\end{array}$ & $\begin{array}{c}2016-2017 \\
N=190\end{array}$ & $\begin{array}{c}\text { Total } \\
N=650\end{array}$ \\
\hline CO in exhaled air [ppm] & $4.1 \pm 4.9$ & $3.9 \pm 4.5$ & $3.3 \pm 4.1$ & $3.8 \pm 4.5$ \\
\hline \multicolumn{5}{|l|}{ Blood pressure [mm Hg]: } \\
\hline Systolic & $137.5 \pm 21.0$ & $135.1 \pm 22.4$ & $133.9 \pm 17.9$ & $135.7 \pm 20.6$ \\
\hline Diastolic & $84.7 \pm 10.6$ & $79.7 \pm 12.3^{*}$ & $79.5 \pm 10.6^{*}$ & $81.6 \pm 11.4$ \\
\hline Total cholesterol [mmol/l] & $4.41 \pm 1.04$ & $4.51 \pm 1.15$ & $4.04 \pm 1.03^{\star \dagger}$ & $4.33 \pm 1.08$ \\
\hline LDL cholesterol [mmol/l] & $2.38 \pm 0.89$ & $2.48 \pm 1.00$ & $2.08 \pm 0.84^{\star \dagger}$ & $2.32 \pm 0.92$ \\
\hline $\mathrm{HDL}[\mathrm{mmol} / \mathrm{l}]$ & $1.34 \pm 0.36$ & $1.30 \pm 0.37$ & $1.27 \pm 0.39$ & $1.31 \pm 0.38$ \\
\hline Triglycerides [mmol/l] & $1.53 \pm 1.06$ & $1.61 \pm 1.13$ & $1.48 \pm 0.84$ & $1.54 \pm 1.02$ \\
\hline Glucose $[\mathrm{mmol} / \mathrm{l}]$ & $5.85 \pm 1.70$ & $6.16 \pm 1.89^{\star}$ & $6.23 \pm 1.60^{*}$ & $6.05 \pm 1.74$ \\
\hline $\mathrm{HbA}_{1 \mathrm{c}}{ }^{\ddagger}(\%)$ & - & $6.19 \pm 0.88$ & $6.13 \pm 0.80$ & $6.15 \pm 0.83$ \\
\hline Body mass index $\left[\mathrm{kg} / \mathrm{m}^{2}\right]$ & $28.2 \pm 4.1$ & $28.2 \pm 4.0$ & $28.9 \pm 4.1$ & $28.4 \pm 4.1$ \\
\hline \multicolumn{5}{|l|}{ Waist circumference $[\mathrm{cm}]$ : } \\
\hline Men & $100.0 \pm 10.4$ & $97.9 \pm 10.0$ & $103.0 \pm 11.0^{* \dagger}$ & $100.3 \pm 10.6$ \\
\hline Women & $91.8 \pm 11.3$ & $95.3 \pm 12.6$ & $97.1 \pm 10.6^{*}$ & $93.9 \pm 11.8$ \\
\hline
\end{tabular}

HDL - high-density lipoprotein, LDL - low-density lipoprotein. ${ }^{\ddagger}$ Available for 105 patients in 2011-2013 and 187 patients in 2016-2017, not measured in 2006-2007. ${ }^{*} p<0.05$ vs. 2006-2007, ${ }^{\dagger} p<0.05$ vs. 2011-2013.

contradict the benefits arising from the rapid development of pharmacological and invasive treatment of coronary artery disease observed in recent years $[8,19,20]$.

The present analysis shows no significant improvement in the control of the main CAD risk factors and no significant change in the proportion of patients reporting the use of antiplatelets, $\beta$-blockers, and lipid-lowering drugs 6-18 months after discharge from the hospital. Importantly, when we used the LDL cholesterol goal as recommended in the ESC guidelines at the time of each survey, the proportion of patients reaching their LDL cholesterol goal decreased significantly [21-23]. This finding could be explained by the insufficient increase in doses of lipid-lowering drugs. In addition, an increased waist circumference could also play a role. In addition, the increase in BMI and waist (especially prominent among females) could also influence the effectiveness of treatment of hypertension and diabetes. Furthermore, the comparison of the secondary prevention coefficient across the surveys likewise failed to provide any evidence of an improvement in the quality of medical care in the field of secondary prevention of CAD. Moreover, the multivariable analysis of the secondary prevention coefficient suggests even a decreased coefficient in the second as compared to first survey. Taking all these factors into consideration, the present results suggest that there is still a considerable potential for reducing cardiovascular risk in patients after myocardial revascularization.

Traditional cardiac rehabilitation programs are less effective for patients with a lower level of education and tend to be less efficient in patients after non-emergency myocardial revascularization compared to subjects with acute coronary syndromes [24, 25]. Indeed, several recent initiatives have aimed at improving cardiovascular risk through education-based secondary prevention programs [26-28].

The present analysis presents a considerable change in the characteristics of patients undergoing myocardial revascularization, including the difference in age and education, as well as a shift in the management of coronary patients. Indeed, although we used the same inclusion criteria $62 \%$ of analyzed patients underwent PCI and $38 \%$ CABG in 2006-2007 whereas the corresponding proportions of patients undergoing $\mathrm{PCI}$ and $\mathrm{CABG}$ in 2016-2017 were $90 \%$ and $10 \%$.

In summary, our results suggest decreasing mean LDL cholesterol and blood pressure, but increasing mean fasting glucose and waist circumference in patients with established CAD. Among participants of the last survey $17 \%$ were smokers, $39 \%$ had high blood pressure, $62 \%$ high LDL cholesterol, $20 \%$ high fasting glucose, $41 \%$ were obese and $57 \%$ had central obesity.

Our analysis has some limitations. Firstly, the participants were limited to those who had experienced an elective myocardial revascularization procedure. As a consequence, our results should not be directly applied to other CAD patients. Secondly, the participants of the surveys lived in a defined geographical area. Although the applicability of our results to other regions is uncertain, the observed trends accord with changes over time in the gener- 

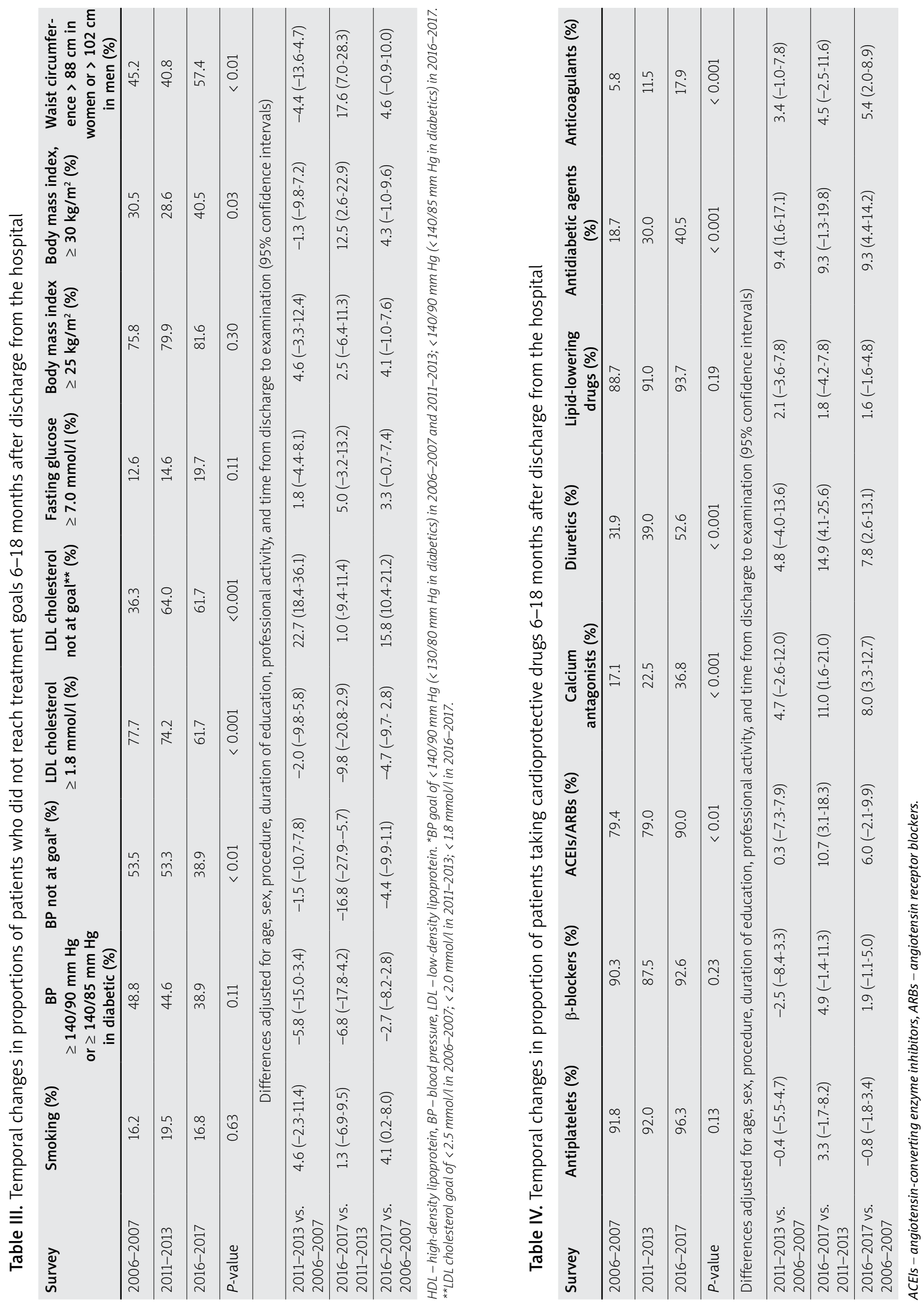


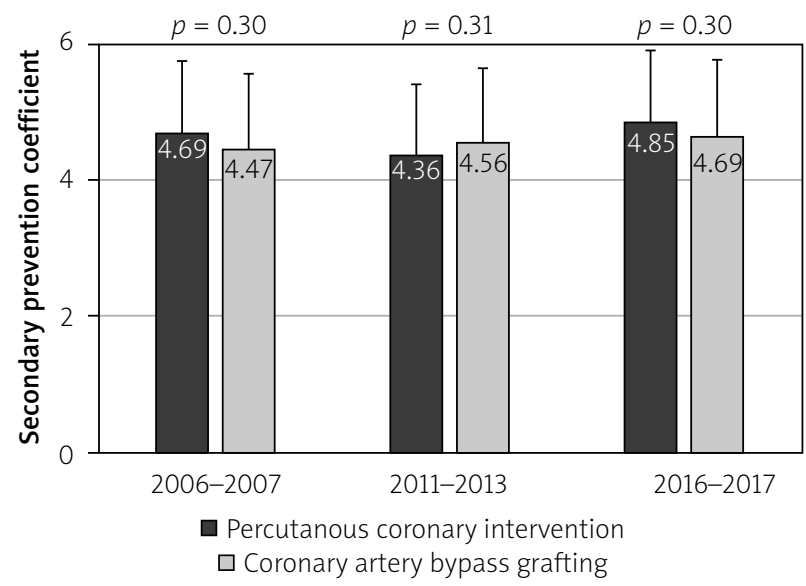

Figure 1 . Mean values of the secondary prevention coefficient to myocardial revascularization procedure and survey

al population in Poland as well as in patients with CAD in other European countries [6, 29]. Thirdly, we could not analyze the dosages of prescribed drugs and lifestyle habits of the surveys participants, which could even increase the impact of the present results. Further studies should aim at estimating individual drug doses and lifestyle factors.

\section{Conclusions}

The analysis of three multicenter surveys provides evidence of a considerable potential for further improvement in cardiovascular risk in revascularized patients. Moreover, our data suggest no consistent improvement in the effectiveness of secondary prevention efforts.

\section{Acknowledgments}

The authors are grateful to the administrative staff, physicians, nurses and other personnel in the hospitals in which the survey was carried out and to all patients who participated in the surveys.

\section{Conflict of interest}

The authors declare no conflict of interest.

\section{References}

1. Wilkins E, Wilson L, Wickramasinghe K, et al. European Cardiovascular Disease Statistics 2017. Brussels: European Heart Network; 2017. Available at: http://www.ehnheart.org/cvd-statistics/cvd-statistics-2017.html

2. Szummer K, Lindhagen L, Evans M, et al. Treatments and mortality trends in cases with and without dialysis who have an acute myocardial infarction: an 18-year nationwide experience. Circ Cardiovasc Qual Outcomes 2019; 12: e005879.

3. Gierlotka M, Zdrojewski T, Wojtyniak B, et al. Incidence, treatment, in-hospital mortality and one-year outcomes of acute myocardial infarction in Poland in 2009-2012--nationwide AMIPL database. Kardiol Pol 2015; 73: 142-58.

4. Piepoli MF, Hoes AW, Agewall S, et al. 2016 European Guidelines on cardiovascular disease prevention in clinical practice. The
Table V. Factors related to the value of the secondary prevention coefficient in multivariable regression analysis

\begin{tabular}{lcc} 
Variable & $\begin{array}{c}\beta \pm \text { standard } \\
\text { error }\end{array}$ & $P$-value \\
\hline \begin{tabular}{l} 
Survey: \\
\hline $2011-2013$ vs. 2006-2007
\end{tabular} & $-0.16 \pm 0.05$ & $<0.001$ \\
\hline $2016-2017$ vs. 2011-2013 & $0.05 \pm 0.06$ & 0.21 \\
\hline Age [years] & $0.15 \pm 0.05$ & $<0.01$ \\
\hline Duration of education [years] & $0.09 \pm 0.04$ & 0.04 \\
\hline Sex (male - 1, female - 0) & $-0.05 \pm 0.04$ & 0.21 \\
\hline Employment (yes - 1, no - 0) & $0.05 \pm 0.05$ & 0.26 \\
\hline PCI (PCI - 1, CABG - 0) & $0.04 \pm 0.04$ & 0.40 \\
\hline $\begin{array}{l}\text { Time from the index hospitalization } \\
\text { to examination [years] }\end{array}$ & $-0.03 \pm 0.05$ & 0.56 \\
\hline CABG - coronaty atey bypass grafing, $P C l-$ & &
\end{tabular}

$C A B G$ - coronary artery bypass grafting, $P C I$ - percutaneous coronary intervention.

Sixth Joint Task Force of the European Society of Cardiology and Other Societies on Cardiovascular Disease Prevention in Clinical Practice. Eur Heart J 2016; 37: 2315-81.

5. Jankowski P, Czarnecka D, Badacz L, et al. Practice setting and secondary prevention of coronary artery disease. Arch Med Sci 2018; 14: 979-87.

6. Kotseva K, De Bacquer D, Jennings C, et al. Time trends in lifestyle, risk factor control, and use of evidence-based medications in patients with coronary heart disease in Europe: results from 3 EUROASPIRE Surveys, 1999-2013. Glob Heart 2017; 12: 315-22.

7. Jernberg T, Hasvold P, Henriksson M, et al. Cardiovascular risk in post-myocardial infarction patients: nationwide real world data demonstrate the importance of a longterm perspective. Eur Heart J 2015; 36: 1163-70.

8. Kotseva K, De Backer G, De Bacquer D, et al. Lifestyle and impact on cardiovascular risk factor control in coronary patients across 27 countries: results from the European Society of Cardiology ESC-EORP EUROASPIRE V registry. Eur J Prev Cardiol 2019; 26: 824-35.

9. Pajak A, Jankowski P, Kawecka-Jaszcz K, et al. Changes in secondary prevention of coronary artery disease in the post-discharge period over the decade 1997-2007. Comparison of Cracovian Program for Secondary Prevention of Ischaemic Heart Disease and Polish parts of EUROASPIRE II and EUROASPIRE III surveys. Kardiol Pol 2009; 67: 1353-9.

10. Jankowski P, Czarnecka D, Łysek R, et al. Secondary prevention in patients after hospitalization due to coronary artery disease: what has changed since 2006? Kardiol Pol 2014; 72: 355-62.

11. Jankowski P, Kosior DA, Sowa P, et al. Secondary prevention of coronary artery disease in Poland. Results from the POLASPIRE Survey. Cardiol I 2020; 27: 533-40.

12. Montalescot G, Sechtem U, Achenbach S, et al. Task Force Members, ESC Committee for Practice Guidelines, Document Reviewers. 2013 ESC guidelines on the management of stable coronary artery disease: the Task Force on the management of stable coronary artery disease of the European Society of Cardiology. Eur Heart J 2013; 34: 2949-3003. 
13. Neumann FJ, Sousa-Uva M, Ahlsson A, et al. 2018 ESC/EACTS Guidelines on myocardial revascularization. Eur Heart J 2019; 40: 87-165.

14. Knuuti J, Wijns W, Saraste A, et al. 2019 ESC Guidelines for the diagnosis and management of chronic coronary syndromes: The Task Force for the diagnosis and management of chronic coronary syndromes of the European Society of Cardiology. Eur Heart J 2020; 41: 407-77.

15. Maron DJ, Hochman JS, Reynolds HR, et al. Initial Invasive or Conservative Strategy for Stable Coronary Disease. N Engl J Med 2020; 382: 1395-407.

16. Spertus JA, Jones PG, Maron DJ, et al. Health-status outcomes with invasive or conservative care in coronary disease. $\mathrm{N}$ Engl J Med 2020; 382: 1408-19.

17. Frye RL, August P, Brooks MM, et al.; BARI 2D Study Group. A randomized trial of therapies for type 2 diabetes and coronary artery disease. N Engl J Med 2009; 360: 2503-15.

18. Hueb W, Lopes N, Gersh B, et al. Ten-Year follow-up survival of the medicine, angioplasty, or surgery study (MASS II). Circulation 2010; 122: 949-57.

19. Kotseva K, Wood D, De Bacquer D, et al. EUROASPIRE IV: a European Society of Cardiology survey on the lifestyle, risk factor and therapeutic management of coronary patients from 24 European countries. Eur J Prev Cardiol 2016; 23: 636-48.

20. Jankowski P, Kozieł P, Bogacki P, et al. Pharmacotherapy in patients with chronic coronary syndromes over a 20-year period (1997-2017). Kardiol Pol 2020; 78: 1156-8.

21. De Backer G, Ambrosioni E, Borch-Johnsen K, et al. European guidelines on cardiovascular disease prevention in clinical practice: Third Joint Task Force of European and other Societies on Cardiovascular Disease Prevention in Clinical Practice. Eur Heart J 2003; 24: 1601-10.

22. Graham I, Atar D, Borch-Johnsen K, et al. European guidelines on cardiovascular disease prevention in clinical practice: executive summary: Fourth Joint Task Force of the European Society of Cardiology and Other Societies on Cardiovascular Disease Prevention in Clinical Practice. Eur Heart J 2007; 28: 2375-414.

23. Perk J, De Backer G, Gohlke H, et al. European guidelines on cardiovascular disease prevention in clinical practice. The Fifth Joint Task Force of the European Society of Cardiology and Other Societies on Cardiovascular Disease Prevention in Clinical Practice. Eur Heart J 2012; 33: 1635-701.

24. Jankowski P, Pająk $A$, Łysek $R$, et al. Cardiac rehabilitation in real life. Medicine 2015; 94: e1257.

25. Wójcicki K, Krycińska R, Tokarek T, et al. Knowledge and prevalence of risk factors for coronary artery disease in patients after the first and repeated percutaneous coronary intervention. Kardiol Pol 2020; 78: 147-53.

26. Jankowski P, Niewada M, Bochenek A, et al. Optimal model of comprehensive rehabilitation and secondary prevention. Kardiol Pol 2013; 71: 995-1003.

27. Siudak Z, Pers M, Dusza K, et al. The efficacy of an education-based secondary outpatient prevention programme after acute coronary syndrome hospitalisations and treatment in poland. The patient club initiative. Kardiol Pol 2016; 74: 185-91.

28. Pająk A, Wolfshaut-Wolak R, Doryńska A, et al. Longitudinal effects of a nurse-managed comprehensive cardiovascular disease prevention program for hospitalized coronary heart disease patients and primary care high-risk patients. Kardiol Pol 2020; 78: 429-37.
29. Piwońska A, Piotrowski W, Kozela M, et al. Cardiovascular diseases prevention in Poland: results of WOBASZ and WOBASZ II studies. Kardiol Pol 2018; 76: 1534-41. 